\title{
Tensiones entre el Tratado sobre Integración y Complementación Minera y la "Ley de Glaciares" en Argentina
}

Tensions between the Mining Integration and Complementation Treaty and the "Glacier Law" in Argentina

\author{
Celia Romina Bruculo ${ }^{1}$ \\ María Laura Isla Raffaele ${ }^{2}$
}

\section{Resumen}

En un contexto de expansión del modelo extractivo en América Latina, en 1997 Argentina y Chile firmaron el Tratado sobre Integración y Complementación Minera con el fin de posibilitar las inversiones en las zonas fronterizas en un área geopolíticamente estratégica, lo que habilitó un espacio para el desarrollo de esta actividad sin restricciones superpuestas entre ambos países. En ese marco, se aprobó el primer megaproyecto binacional, Pascua Lama, propiedad de la empresa Barrick Gold, fuertemente cuestionado en ambas partes de la cordillera debido a sus impactos ambientales. En Argentina la sanción de la Leyes de Presupuestos Mínimos para la Preservación de los Glaciares y del Ambiente Periglacial (Ley 26.418/2008, Ley 26.639/2010), que prohibió la minería sobre esas áreas, fue percibida por el sector minero como una amenaza a sus intereses económicos. Tomando como enfoques teóricos la Ecología Política y las Relaciones Internacionales, este trabajo tiene por objetivo analizar las tensiones que surgen entre el Tratado binacional y la "Ley de Glaciares" en relación con los intereses mineros y la conservación de los ecosistemas glaciares y periglaciales. Se analizan aspectos socioambientales, legales, políticos y corporativos, considerando la complejidad de la coexistencia de ambos instrumentos jurídicos en un extenso territorio binacional.

Palabras claves: Tratado Binacional sobre Integración y Complementación Minera, Pascua Lama, Barrick Gold, Ley de Glaciares

\footnotetext{
Recibido: 30 de octubre de 2020 Aceptado: 4 de diciembre de 2020 Publicado: 1 de enero de 2021

${ }^{1}$ Doctora en Relaciones Internacionales. Becaria Posdoctoral CONICET (Facultad de Filosofía y Letras, Universidad de Buenos Aires, UBA). Docente de la Universidad Nacional de La Rioja y la Universidad Tecnológica Nacional (Facultad Regional La Rioja), Argentina. Correo electrónico: rominabruculo@gmail.com

${ }^{2}$ Licenciada en Ciencias Ambientales, Becaria doctoral CONICET (Facultad de Filosofía y Letras, Universidad de Buenos Aires -UBA-) y docente de la Facultad de Agronomía UBA, Argentina. Correo electrónico: isla@agro.uba.ar
} 


\section{Abstract}

In a context of expansion of the extractive model in Latin America, in 1997 Argentina and Chile signed the Treaty on Mining Integration and Complementation in order to enable investments in border areas in a geopolitically strategic area, which provided a space for development of this activity without overlapping restrictions between both countries. In this framework, the first binational megaproject, Pascua Lama, property of Barrick Gold company, was approved, strongly questioned in both countries due to its environmental impacts. In Argentina, sanction of the Laws on Minimum Standards for the Preservation of Glaciers and the Periglacial Environment (Law 26.418/2008, Law 26.639/2010), which prohibited mining in these areas, was perceived by the mining sector as a threat to its economic interests. Taking Political Ecology and International Relations as theoretical approaches, this article analyze the tensions that arise between the binational Treaty and the "Glacier Law" in relation to mining interests and the conservation of glacial and periglacial ecosystems. Socio-environmental, legal, political and corporate aspects are analyzed, considering the complexity of the coexistence of both legal instruments in an extensive binational territory.

Keywords: Mining Integration and Complementation Treaty, Pascua Lama, Barrick Gold, Glacier Law

\section{Introducción}

América Latina fue ingresada al sistema económico mundial como proveedora de materias primas desde los albores colonialistas, abasteciendo de minerales a las potencias europeas. A principio del siglo XX, comenzaron a instalarse en la región nuevos monopolios económicos-financieros con el fin de colonizar áreas para la inversión trasnacional (Villamil Velásquez, 2012). Paulatinamente, el proceso de globalización fue afianzando el poder de diversos actores a escala mundial, particularmente de las empresas multinacionales que fueron adquiriendo un papel destacado en el sistema internacional. Las dimensiones internas del Estado y su capacidad soberana comenzaron a coexistir con una estructura compleja de actores y múltiples relaciones que hacen de éstos, estructuras cada vez más permeables a una serie de influjos endógenos y exógenos, tanto desde lo público como desde los ámbitos privados (Keohane y Nye, 1988) ${ }^{3}$.

\footnotetext{
${ }^{3}$ Keohane y Nye (1988:22) definen a la interdependencia como "situaciones caracterizadas por efectos recíprocos entre países o entre actores en diferentes países”, y como producto de los intercambios internacionales que crecieron fuertemente a partir de la segunda guerra mundial. En la configuración de la interdependencia se entremezclan intereses internos, transnacionales y gubernamentales; y las políticas interna
} 
Hacia fin del siglo pasado, en un contexto de libre mercado y caída de las barreras comerciales en los países latinoamericanos, se produjo un ingreso masivo de empresas mineras trasnacionales (principalmente de capitales norteamericanos y europeos), denominado "boom minero" (Machado Aráoz, 2010), que impulsó el desarrollo de la megaminería a cielo abierto en la región, la cual implicó el despliegue de importantes infraestructuras en grandes superficies que en algunos casos hasta logró traspasar las fronteras internacionales.

Distintos autores coinciden en que la minería a gran escala se ha convertido en un caso paradigmático del modelo extractivista que se generalizó en América Latina desde la década de 1970 (Gudynas, 2009; Giarracca y Teubal, 2010; Acsebrud, 2012). El mismo está basado en la explotación de recursos naturales por parte de empresas transnacionales que dominan sectores claves de la producción y la tecnología, para su venta en el mercado mundial (Seoane, 2012; Svampa y Antonelli, 2009; Svampa et al, 2009). Este modelo se encuadra en lo que Harvey denomina (2007: 165) un proceso de "acumulación por desposesión", característico de la actual etapa del capitalismo, que involucra la mercantilización y privatización de la tierra, el desalojo de comunidades campesinas, la conversión de diversas formas de derechos de propiedad en derechos de propiedad exclusivos, la supresión del derecho a los bienes comunes, la apropiación de los recursos naturales, la transformación de la fuerza de trabajo en mercancía, la eliminación de formas de producción y consumo alternativos, el endeudamiento estatal y la extensión del sistema de créditos.

De esta forma, la minería a cielo abierto pone de manifiesto una lógica de expropiación económica, ecológica y geográfica del territorio (Machado Aráoz, 2010). Según Gudynas, se ha desarrollado "una nueva geografía basada en licencias mineras que desplazan a comunidades locales, anulan otros circuitos productivos o rompen con territorios ancestralmente delimitados" (2012: 133). La promoción de la minería a gran escala se propone como modelo de desarrollo con una "narrativa desarrollista" compartida por los actores interesados (estados y empresas transnacionales) que a modo de legitimarse socialmente se autodefinen como hacedores de una minería responsable y sustentable, aunque la realidad dista de esos patrones (Svampa, 2008).

En este contexto de expansión del modelo extractivo y de relaciones de interdependencia en América Latina, en 1997 Argentina y Chile firmaron el "Tratado sobre Integración y Complementación Minera" con el fin de promover inversiones

\footnotetext{
y externa comienzan a eslabonarse estrechamente. La interdependencia plantea un esquema en el que los estados asumen cierta "vulnerabilidad" y/o "sensibilidad" respecto de los intercambios mutuos, necesidades correlativas, ventajas y debilidades que se establecen respecto de requerimientos que son demandados tanto desde el sistema interestatal como desde otros actores posicionados en el sistema internacional (Ibid.).
} 
en las zonas fronterizas en un área geopolíticamente estratégica, lo que habilitó un espacio para el desarrollo de esta actividad sin restricciones superpuestas entre ambos países.

Dos años más tarde, firmaron el protocolo específico que regularía las operaciones del primer proyecto binacional, Pascua Lama, propiedad de la empresa Barrick Gold, fuertemente cuestionado por comunidades y movimientos ambientalistas como otros referentes sociales de ambas partes de la cordillera debido al uso excesivo del recurso hídrico, el riesgo de contaminación ambiental y la propuesta de remover glaciares que se localizan en el área del yacimiento, entre otros impactos.

Una década después, en un contexto de movilizaciones sociales en contra del extractivismo minero en América Latina, en Argentina se sancionó la "Ley de Glaciares" (Ley de Presupuestos Mínimos para la Preservación de los Glaciares y del Ambiente Periglacial - Ley 26.639/2010) ${ }^{4}$, norma ambiental que, entre otros instrumentos, estableció la prohibición de la actividad minera en las áreas bajo su protección.

Tomando como enfoques teóricos, el campo de la ecología política y las relaciones internacionales, este trabajo tiene por objetivo analizar las tensiones que surgen entre el Tratado binacional y la Ley de Glaciares en relación con los intereses mineros (corporaciones multinacionales, gobiernos nacionales y subnacionales) y la conservación de los ecosistemas glaciares y periglaciales en Argentina. Se analizan aspectos socioambientales, legales, políticos y corporativos, considerando la complejidad de la coexistencia de ambos instrumentos jurídicos en un extenso territorio binacional.

La propuesta metodológica consiste en el análisis documental de fuentes primarias y secundarias desde un abordaje institucional-político con eje en los instrumentos formales (el Tratado bilateral y la norma nacional). Entre las fuentes primarias se analiza la legislación citada y protocolos complementarios. Las fuentes secundarias provienen de antecedentes y estudios previos de las autoras que se enfocaron en cada instrumento normativo, también se trabajó con artículos académicos, informes periodísticos y documentos públicos (fallos judiciales, estudios de impacto ambiental, auditorías ambientales, informes técnicos).

Este artículo se estructura en cuatro partes: En la primera se exponen las características salientes del sistema normativo minero de Argentina; luego se analiza el Tratado sobre Integración y Complementación Minera en función de sus objetivos

\footnotetext{
${ }^{4}$ Las leyes de presupuestos mínimos son normas que conceden una tutela ambiental uniforme para todo el territorio nacional, y tienen por objeto imponer condiciones necesarias para asegurar la protección ambiental (Ley 25.675/2002).
} 
y cuestionamientos; en la tercera sección se describe la trayectoria de la Ley de Glaciares de Argentina y los principales obstáculos generados desde el lobby minero; por último, se presentan reflexiones finales en relación a la implementación y contradicciones de estos instrumentos normativos.

\section{Leyes y políticas mineras en Argentina}

Durante la década de 1990, algunos países latinoamericanos con potencial minero efectuaron reformas en sus legislaciones con el fin de atraer inversiones extranjeras para el sector, dentro de los cuales se encuentra Argentina (CEPAL, 2002). Estas medidas fueron incentivadas por organismos internacionales como el Banco Mundial, que desde 1988 brindó asistencia técnica a los estados bajo la orientación de un conjunto de políticas privatizadoras y desreguladoras de la economía (Banco Mundial, 2013). Para el caso argentino, se impulsó el Programa de Asistencia a la Minería Argentina (PASMA) con el objetivo de proponer medidas regulatorias e institucionales para fomentar y proteger las futuras inversiones extranjeras del sector (Svampa et al, 2009). Cabe considerar que Argentina a diferencia de otros países andinos no poseía una larga tradición productiva minera a gran escala (Svampa y Álvarez, 2010).

En este contexto se llevó a cabo una reforma del estado y se sancionaron leyes de promoción minera que sirvieron de marco para promover la instalación de empresas trasnacionales (Acsebrud, 2012; Prado, 2005; Svampa et al, 2009). Entre ellas se destacan las normas orientadas a fomentar las inversiones a partir del otorgamiento de diversos beneficios económicos a la actividad, como la Ley Nacional de Inversiones Mineras (Ley 24.196/1993) ${ }^{5}$, la Ley de Reordenamiento Minero (Ley $24.224 / 1993)^{6}$ y el Acuerdo Federal Minero (Ley 24.228/1993) ${ }^{7}$. Por su parte, la modificación del Código de Minería también contribuyó al aumento de la inversión extranjera al considerar a las minas como bienes privados e impedir al estado el derecho de explotar y disponer de ellas, confiriendo a los particulares la facultad de buscar minas, aprovecharlas y disponer de ellas como dueños por tiempo ilimitado. Asimismo, la reforma de la Constitución Nacional (1994) cedió a las Provincias el

\footnotetext{
${ }^{5}$ La sanción de la Ley Nacional de Inversiones Mineras otorgó importantes beneficios económicos a la minería, como ser la estabilidad fiscal por 30 años, deducciones en el impuesto a las ganancias; exención de derechos, gravámenes y tasas aduaneras para importación de bienes de capital, equipos e insumos para desarrollar los proyectos; fijación de un tope de 3\% del valor boca mina para el cobro de regalías, entre otros.

${ }^{6}$ La Ley de Reordenamiento Minero determinó la realización de las cartas geológicas a cargo de la Secretaría de Minería, de forma que el Estado provea de información a las empresas mineras y asumiera esos costos.

${ }^{7}$ El Acuerdo Federal Minero estableció el compromiso de todas las provincias argentinas a atraer inversiones extranjeras; a eliminar gravámenes, tasas municipales e impuestos que afectaran a la minería; y a evitar distorsiones en las tarifas de los servicios.
} 
dominio originario de los recursos naturales existentes en su territorio, lo que significó una marcada descentralización en el uso y control de esos recursos ${ }^{8}$.

Todas estas medidas orientadas a atraer capitales extranjeros generaron un gran crecimiento de la inversión privada, aumentando la prospección y exploración minera en el país. Argentina se transformó, en un periodo menor a una década, en el primer país en captación de inversiones mineras (Wagner, 2010), poseyendo en 2011 más de 614 proyectos (Minería en números, 2012).

A partir de 1997 con la puesta en producción de los proyectos Bajo de la Alumbrera (oro y cobre), Cerro Vanguardia (oro y plata) y Salar del Hombre Muerto (litio) se produjo un cambio en la estructura minera. Del predominio de la explotación de carbón y rocas de aplicación comenzó a cobrar gran magnitud la explotación de minerales metalíferos (Prado, 2005). Las exportaciones minerometalíferas crecieron casi un $9 \%$ durante la década de los noventa y continuaron aumentando hasta superar los 3.490 millones de dólares en 2015, representando el 6\% de las exportaciones totales del país (Ministerio de Hacienda y Finanzas Públicas, 2016).

Los gobiernos posteriores a la década de 1990 continuaron impulsando la actividad minera como política de Estado. En 2004 se presentó el Plan Nacional Minero cuyo objetivo consistió en consolidar el proceso de inversión y desarrollo minero en el país. Dos años más tarde se lanzó el Plan de Reactivación de la Actividad Nuclear con el fin de reiniciar la producción de uranio (Wagner, 2010). En 2012, bajo instancia del gobierno nacional, se creó la Organización Federal de Estados Mineros (OFEMI) con la premisa de fortalecer el sector en las provincias cordilleranas (Jujuy, Salta, Catamarca, La Rioja, San Juan, Mendoza, Chubut, Neuquén, Río Negro y Santa Cruz), pese a que algunas registraban altos niveles de conflictividad en rechazo de la actividad, incluso dos contaban con leyes que limitan la minería a cielo abierto en sus territorios; asimismo, entre 2015 y 2019 se sumaron medidas orientadas a promover el ingreso de inversiones en el sector, como la eliminación de las retenciones a las exportaciones mineras que habían sido introducidas años atrás y la iniciativa de elaborar un nuevo Acuerdo Federal Minero ${ }^{9}$ que, hasta la actualidad, no logró ser ratificado por el congreso nacional ni por las provincias implicadas.

\footnotetext{
${ }^{8}$ La Constitución establece que la Nación posee la facultad de dictar las normas de presupuestos mínimos de protección ambiental y que las provincias tienen la potestad de sancionar leyes complementarias, las cuales pueden ser más exigentes, pero nunca inferiores a la tutela que otorga la Nación. De esta forma, si bien los estados provinciales poseen el dominio de los recursos naturales, para su uso deben cumplir con los estándares ambientales que fija el Estado Nacional.

${ }^{9}$ En 2017, el denominado "Nuevo Acuerdo Federal Minero" fue firmado por el Gobierno Nacional y catorce provincias (San Juan, Santa Cruz, Mendoza, Rio Negro, Jujuy, Entre Ríos, Buenos Aires, Tierra Del Fuego, Córdoba, Catamarca, Corrientes, Salta, Neuquén, Misiones). Entre sus principales objetivos se encuentra la
} 
Con respecto a la administración minera, la autoridad a nivel nacional es la Secretaría de Minería, cuyas funciones consisten en implementar políticas uniformes en todo el país a través de la aplicación de las normativas (como la Ley de Inversiones y la Ley de Reordenamiento Minero), planes y acuerdos. Al ser un país federal y como la administración de los recursos naturales es competencia de las provincias, éstas poseen sus propias agencias bajo la forma de ministerios, secretarías o direcciones, las cuales conforman las autoridades competentes en la materia y son las encargadas de autorizar las concesiones de los yacimientos ubicados en sus jurisdicciones (CEPAL, 2002). Asimismo, existe el Consejo Federal de Minería (COFEMI) que funciona como un órgano asesor con representantes de nación y las provincias.

\section{El Tratado sobre Integración y Complementación Minera entre la República de Chile y la República Argentina}

A finales del siglo XX, el consolidado modelo minero en Chile y la reciente instalación de la actividad minera en Argentina encontraron un resorte más para la integración transfronteriza. Ambos estados comenzaron a entablar una serie de acuerdos respaldados en el marco de inversiones propuestas por empresas transnacionales, entre ellas Barrick Gold, una de las compañías más grandes del mundo dedicada a la extracción de oro y que se hallaba en la región desde inicios de la década de 1990 (Díaz Gavier, 2012). El primer emprendimiento que se pretendió desarrollar, y que dio origen al Tratado, fue Pascua Lama, un proyecto localizado en la frontera entre las provincias de San Juan (Argentina) y Huasco (Chile) que consiste en la explotación a cielo abierto de una mina de oro y plata "sobre los glaciares de altura en la región cordillerana" (Svampa y Antonelli, 2009:17). Para que éste y otros proyectos pudiesen llevarse a cabo fue necesario que ambos países adecuen sus marcos normativos para habilitar las operaciones mineras en áreas de frontera (Alcayaga, 2009).

El contexto en el cual tuvo lugar la emergencia del tratado bilateral minero fue de un clima de cooperación política, desregulación económica y facilitación fronteriza. Entre los antecedentes del Tratado se encuentra el restablecimiento de las relaciones pacíficas con el "Tratado de Paz y Amistad" de 1984 en tanto cimiento fundamental para la cooperación en sus diversas dimensiones. En lo económico productivo, se realizó el "Acuerdo de Complementación Económica N¹6" (ACE

homogeneización de los marcos regulatorios provinciales para dar mayor estabilidad a los inversores y aumentar la competitividad a nivel regional, y la centralización de información catastral, geológica y minera por parte de la Secretaria de Minería (Diario de Cuyo, 21/06/2017). 
16) ${ }^{10}$ en 1991, en el marco de ALADI (Asociación Latinoamericana de Integración), al que se anexó el "Protocolo $N^{\circ} 3$ " que establece el aprovechamiento conjunto de los recursos naturales cordilleranos. En el ACE 16 se fueron conformando comisiones binacionales con la participación de actores públicos y privados para la elaboración de lo que posteriormente se cristalizó en el Tratado. Dentro de los antecedentes, también se encuentra el "Tratado de Promoción y Protección Recíproca de Inversiones" de 1991 y las "Bases y Fundamentos de un Tratado de Integración y Complementación Minera Argentina-Chile" suscriptos en 1996. Desde 1994 ambos países sostuvieron encuentros y constituyeron comisiones para el tratamiento minero, varias de estas articuladas en los Comités de Integración argentinoschilenos ${ }^{11}$.

El 29 de diciembre de 1997, los presidentes de ambos países firmaron el "Tratado entre la República de Chile y la República Argentina sobre Integración y Complementación Minera" (TICM), ratificado tres años después por los respectivos parlamentos. Según explicita su artículo 1, el Tratado constituye un marco jurídico que regirá el negocio minero dentro de su ámbito de aplicación y tiene por objeto permitir a los inversionistas de cada país participar en el desarrollo de la integración minera que los estados declaran de utilidad pública e interés general de la nación. También determina que las prohibiciones y restricciones vigentes en las legislaciones referidas a la adquisición de propiedad, ejercicio de la posesión o constitución de derechos sobre bienes raíces, o derechos mineros, establecidas en razón de la calidad de extranjero y de nacional chileno o argentino, no serán aplicables a los negocios mineros regidos por el tratado.

Asimismo, el TICM fue a fondo en materia de concesiones a las grandes empresas mineras, contemplando el "acceso, desempeño y protección de todas las actividades y servicios que tengan relación con el negocio minero (...), incluyen las servidumbres y otros derechos contemplados a favor de las concesiones mineras y las plantas de beneficio, fundición y refinación, del territorio de la otra parte en que se aplique el Tratado" (Art.1). De esta forma creaba un área de operaciones de 340.835 $\mathrm{km}^{2}$, de los cuales $180.165 \mathrm{~km}^{2}$ corresponden a Chile y $160.670 \mathrm{~km}^{2}$ a Argentina, representando el $25 \%$ y el $6 \%$ del territorio nacional, respectivamente.

En materia ambiental estableció que los países aplicarían sus legislaciones nacionales sobre protección ambiental, sometiendo las actividades mineras al

\footnotetext{
${ }^{10}$ En el marco del ACE 16, Chile y Argentina suscribieron diversos instrumentos destinados a promover la integración energética, en particular, respecto de la interconexión gasífera y suministro de gas natural.

${ }^{11}$ Los Comités de Integración se constituyeron como foros que comprenden provincias argentinas y regiones chilenas a partir de 1997, en los que participan autoridades de las cancillerías y representantes subnacionales de ambos países como, asimismo, actores públicos y privados para el tratamiento de temas comunes en amplios rubros.
} 
Sistema de Evaluación de Impacto Ambiental en Chile y a la Declaración de Impacto Ambiental en Argentina (Art. 12). A su vez, los Estados se comprometieron a intercambiar información relevante de los principales efectos ambientales de cada proyecto minero. Dos años más tarde, en 1999, tuvo lugar la firma de su Protocolo Complementario y en 2001 se constituyó la Comisión Administradora ${ }^{12}$ de dicho Tratado. En ese marco se establecieron una serie de Protocolos específicos que regulan la explotación integrada de yacimientos compartidos por ambos países, proporcionando un marco legal y tributario a cinco proyectos mineros: Pascua Lama (cuyo Protocolo Adicional fue firmado en 2004), Vicuña (en etapa de Prospección y/o Exploración), Amos-Andrés (en etapa de Prospección y/o Exploración), Las Flechas (en etapa de Prospección y/o Exploración) y El Pachón (en proceso de adecuación al Tratado) (Bruculo, 2016).

Cabe destacar que la jerarquía de los tratados internacionales en el derecho interno varía entre ambos países. La Constitución Argentina establece de modo explícito que los tratados internacionales son superiores a las leyes nacionales y que determinados tratados e instrumentos internacionales en materia de derechos humanos poseen jerarquía constitucional o pueden alcanzarla (Drnas de Clément, s/f). En Chile, en cambio, la Constitución no regula de manera expresa ni la forma de dar fuerza normativa al texto de un tratado, ni la función normativa que ha de cumplir una vez que adquiere dicho carácter, pero sí reviste al Ejecutivo celebrarlos y luego ser aprobados o desechados por el Congreso -no modificado por este- (Aldunate Luzana, 2010).

Según Julián Alcayaga (2009), el TICM tuvo tres objetivos principales: permitir que los minerales de Argentina pudieran salir por puertos chilenos, levantar las restricciones a la propiedad extranjera en las zonas limítrofes y transformar la extensa cordillera chileno-argentina en un "país o territorio virtual" que quedaría bajo una sui generis administración de las empresas multinacionales mineras ${ }^{13}$. Si bien, esa suerte de "país virtual" que auguraban desde diversos sectores no pudo constituirse efectivamente, si logró despejar una serie de restricciones al capital privado

\footnotetext{
${ }^{12}$ La Comisión Administradora es el órgano permanente de coordinación, administración y evaluación del Tratado y sus protocolos, teniendo como funciones principales implementar los mecanismos necesarios para garantizar la ejecución del Tratado, desarrollar acciones pertinentes conducentes a la suscripción de los Protocolos Adicionales Específicos en los negocios mineros y participar en la solución de controversias. Esta Comisión se encuentra conformada por los ministerios de relaciones exteriores y las autoridades nacionales en materia de minería de ambos países.

${ }^{13}$ Las investigaciones de Alcayaga (2009) y Rodriguez Pardo (2011) revelan que durante la década 1990 grandes compañías extranjeras prospectaron y/o adquirieron propiedades en áreas no habilitadas por las normas de soberanía en ambos países, como Barrick Gold en Pascua Lama y Cambior S.A. en El Pachón; por lo que en el Tratado fue necesario eliminar esa prohibición para que esas empresas pudieran explotar esos yacimientos mineros.
} 
transnacional que habilitaron la propiedad en áreas de frontera, independientemente de las contradicciones con otros instrumentos legales e intereses precedentes y posteriores a su aplicación (Alcayaga, 2009). De esta forma, el TICM posibilitó las inversiones en un área geopolíticamente estratégica, habilitando un espacio para el desarrollo de la actividad minera sin restricciones permanentes y superpuestas por parte de los Estados, configurando una suerte de soberanía supranacional, es decir un "territorio donde se desdibujan las fronteras y se genera una legalidad propia de los intereses mineros" (Svampa et al, 2009:35). Especialistas de ambos países consideran que desde su concepción el TICM, único en su especie, estuvo viciado por defectos de forma y de fondo (Alcayaga, 2009; Bonasso, 2011; Rodriguez Pardo, 2011; Svampa et al, 2009). Diversas contradicciones con leyes nacionales evidenciaron que al menos se trataba de un instrumento cuestionable, pudiéndose mencionar a priori algunas contradicciones manifiestas con la vigencia del Tratado y las legislaciones e intereses nacionales.

En ese sentido se hace referencia al corpus normativo que regula las zonas de seguridad y frontera en cada país que quedó relegado por el dominio territorial del Tratado. En Argentina, el Decreto Ley 15385/1944 (vigente en la actualidad) creó dichas zonas destinadas a complementar las previsiones territoriales de la defensa nacional que comprenden una faja a lo largo de la frontera terrestre y marítima, cuyo ancho será variable y fijado por el Poder Ejecutivo según intereses de la defensa nacional; asimismo, determinó que los bienes ubicados en la zona de seguridad pertenecen a ciudadanos argentinos nativos, y que la Comisión Nacional de Zonas de Seguridad ejerce la policía de radicación con relación a las transmisiones de dominio o arrendamiento en virtud de los cuales debe entregarse la posesión de inmuebles a cuyo efecto acordará o denegará las autorizaciones correspondientes. De esta forma, según esta norma las concesiones mineras en territorios fronterizos y zonas de seguridad deberían ser autorizados por dicha Comisión que tiene como misión velar por los intereses de la defensa nacional. En Chile, el Decreto Ley №1939/1977 estableció que las tierras fiscales localizadas dentro de los 10 kilómetros de la frontera sólo pueden ser obtenidas en propiedad o arrendamiento por personas naturales o jurídicas chilenas. Así, ambas restricciones a la propiedad en zonas de frontera quedaron rebasadas por el Tratado de Integración y Complementación Minera.

Pese a que el tratado tuvo un fuerte respaldo de los poderes ejecutivos y legislativos de ambas partes, además del gran lobby empresario, su operatividad se vio opacada por diversos motivos, entre ellos: la oposición de senadores chilenos, el proceso de conflictividad por el proyecto Pascua Lama en ambos lados de la Cordillera de los Andes y la sanción de la Ley de Glaciares en Argentina. 
A horas de que el Congreso chileno aprobara el TICM, trece senadores presentaron un requerimiento ante el Tribunal Constitucional, el cual dictaminó en octubre de 2000 y, si bien no lo declaró inconstitucional, le impuso ciertas restricciones, entre ellas que los tribunales no podían acordar servidumbres de paso por Chile a yacimientos mineros que estén fuera de su territorio y que la Comisión Administradora del Tratado no tenía facultades jurisdiccionales, cuestión que entraba en contradicción con la normativa minera chilena (Alcayaga, 2009). Sin embargo, el fallo no impidió que extranjeros exploten zonas de frontera por lo que el núcleo del Tratado mantuvo su propósito.

El proceso de conflictividad en torno a Pascua Lama comenzó en Chile por los cuestionamientos de los pobladores aguas abajo del proyecto por el impacto que podría ocasionar sobre su provisión de agua, que provenía de nevadas y glaciares de la zona donde se iba a construir la mina. Al presentar el Estudio de Impacto Ambiental en 2001, la empresa Barrick Gold omitió la existencia de cuerpos de hielo en el área del emprendimiento. Ante la denuncia de regantes y agricultores chilenos, propuso remover y trasladar tres glaciares (Toro 1, Toro 2 y Esperanza), situación que intensificó el conflicto y generó el rechazo de distintos grupos ambientalistas de ambos países por las consecuencias que ello podría implicar para la conservación de los glaciares (Rodríguez Pardo, 2011; Svampa y Viale, 2014). En 2006 el proyecto fue aprobado en Chile, prohibiéndose la remoción y alteración de esas masas de hielo (Brenning y Azócar, 2010).

Años más tarde, en 2013, las obras en Pascua Lama fueron paralizadas por orden de la Corte Suprema de Chile que ratificó el fallo de la Corte de Apelaciones de Copiapó, la cual exigía la suspensión de las operaciones de Barrick Gold, solicitada por comunidades originarias que observaron que la empresa incumplía las normas de protección de los recursos naturales, más precisamente denunciaban la destrucción de glaciares y la contaminación del recurso hídrico. El fallo estableció que para volver a operar el proyecto minero debía adoptar las medidas necesarias para un adecuado funcionamiento del sistema de manejo de aguas y que la autoridad de aplicación nacional debía monitorear a la empresa para que se atienda a las exigencias legales ambientales (Yornet, 2016). A comienzos de 2018, la Superintendencia del Medio Ambiente (SMA) de Chile ordenó la clausura de Pascua Lama. A pesar de reiterados intentos por parte de la empresa para iniciar la explotación del yacimiento, en septiembre de 2020 la SMA ratificó el cierre definitivo del proyecto.

Del lado argentino también se generó un movimiento de oposición a la vigencia del Tratado en las faenas transcordilleranas, entre las primeras denuncias se encuentra la realizada por el sanjuanino Ricardo Vargas en 2007 ante la Corte 
Suprema de Justicia de la Nación, en la cual le solicita al Alto Tribunal que impida el desarrollo de Pascua Lama por considerar que se incumplían las normas ambientales y que Barrick Gold no contaba con un seguro ambiental de cobertura suficiente para hacer frente a un posible daño ambiental ${ }^{14}$ (Bonasso, 2011; CEDHA, 2013). Además, argumenta que el proyecto contravenía la Ley Nacional de Residuos Peligrosos y la Ley Nacional de Áreas Naturales Protegidas por encontrarse el proyecto emplazado dentro de la Reserva de Biósfera San Guillermo, y que genera importantes impactos ambientales, entre ellos la contaminación de las aguas superficiales y subterráneas y la afectación a los glaciares de la zona (CSJN, 24/04/2012; Yornet, 2016)

Otro obstáculo a la plena implementación del TICM y a la ejecución de Pascua Lama sobrevino en 2008 con la primera sanción de la Ley de Glaciares de Argentina, la cual a su vez fue resistida por Barrick Gold a través de distintos mecanismos que serán tratados en el siguiente apartado.

De esta forma, el tratado fue frustrado en su plena implementación. Los objetivos planteados encontraron diversos obstáculos, por lo que la aspiración a convertir las áreas cordilleranas en fuertes enclaves productivos de complementación minera no ha visto su mayor expresión, al menos eso demuestran una serie de proyectos insertos en él (Bruculo, 2016).

\section{La Ley de Protección de Glaciares en Argentina}

La discusión por la Ley de Glaciares en Argentina se produjo en un contexto internacional de preocupación por los efectos del cambio climático sobre los glaciares y un contexto nacional de expansión megaminera y de la conflictividad en torno a ella $^{15}$ (Isla Raffaele, 2015). A partir del conflicto por Pascua Lama que puso en evidencia los daños que podría ocasionar el emprendimiento a los cuerpos de hielo, en Chile y Argentina comenzaron a elaborarse proyectos de ley para preservar los glaciares ante el avance de actividades extractivas. Si bien los movimientos ambientalistas chilenos fueron pioneros en esta iniciativa, hasta el momento no se ha logrado sancionar. Argentina es el único país del mundo que posee al 2020 una ley de protección de glaciares (Martin y Healey, 2020).

\footnotetext{
${ }^{14}$ En 2009, el sanjuanino Saúl Zeballos presentó otra demanda ante la Corte Suprema por el emprendimiento Veladero, operado por Barrick Gold, que se localiza a $8 \mathrm{~km}$ de Pascua Lama en la provincia de San Juan. Se denunciaba que la empresa operaba incumpliendo normas ambientales nacionales (Ley General del Ambiente, Ley de Gestión Ambiental de Aguas y Ley de Residuos Peligrosos), contaminaba el recurso hídrico y que la mina se encontraba dentro de la Reserva de Biósfera San Guillermo (Seguí, 2016).

${ }^{15}$ El debate por la Ley de Glaciares se produjo en un contexto nacional de surgimiento de múltiples procesos de conflictividad por la megaminería en las localidades donde se instalaron o intentaban instalar proyectos metalíferos (Rojas y Wagner, en prensa).
} 
En 2008, el Congreso Nacional argentino aprobó la primera Ley de Glaciares (Ley 26.418 de Presupuestos Mínimos para la Protección de Glaciares y del Ambiente Periglacial) que consideraba a esos cuerpos de hielo como "reservas estratégicas de recursos hídricos y proveedores de agua" y prohibía la exploración y explotación minera en las zonas de glaciares y ambiente periglacial, entre otras actividades. Semanas después, el Poder Ejecutivo Nacional vetó esta norma esgrimiendo diferentes argumentos; entre ellos, que la norma podría afectar el desarrollo económico de las provincias por la imposibilidad de realizar cualquier tipo de actividad u obra en zonas cordilleranas, y que la restricción de la minería implicaría dar preeminencia a los aspectos ambientales por encima de actividades que podrían llevarse de forma controlada. A su vez, se remarcaba la preocupación de los gobernadores por las implicancias que pudiese tener la Ley sobre el desarrollo económico y las inversiones de sus jurisdicciones (Isla Raffaele, 2015).

Para diversos sectores, el veto a la Ley de Glaciares (Ley 26.418) respondió a las demandas de las provincias cordilleranas y los intereses del sector minero, en especial de Barrick Gold, la cual era propietaria de los principales yacimientos metalíferos de San Juan, Veladero y Lama (Bonasso, 2011; Isla Raffaele, 2015; Bottaro y Sola Álvarez, 2018; Rojas y Wagner, en prensa; Martin y Healey, 2020). La protección del ambiente periglacial podría significar un impedimento para la continuidad de Veladero y obstaculizar la aprobación del Pascua Lama, ya que ambos emprendimientos se encontraban en zona de ambiente periglacial y con presencia de más de 40 glaciares descubiertos, según había informado la empresa en los estudios de impacto ambiental presentados para el inicio de las obras en Argentina (Knight Piésold, 2002 y 2006; Espizúa et al., 2006; CEDHA, 2013).

Mientras continuaban las denuncias por el veto y se desarrollaba el debate legislativo por una nueva Ley de Protección de Glaciares, en abril de 2009 los gobiernos de Chile y Argentina firmaron un acuerdo tributario para definir las regalías de cada país para el proyecto Pascua Lama, el último paso para dar inicio al emprendimiento. A los pocos días, el estado argentino y la empresa anunciaron el comienzo de las obras, las cuales luego serían paralizadas del lado chileno, como se comentó en el apartado anterior. Finalmente, en 2010 se sancionó de forma definitiva la Ley 26.639 de Presupuestos Mínimos para la preservación de los Glaciares y el Ambiente Periglacial, que estableció los lineamientos básicos para la protección de esos ecosistemas con el objeto de preservarlos como reservas estratégicas de recursos hídricos para diversos usos y determinó que los glaciares constituyen bienes de carácter público, lo que significa que se encuentran afectados al uso general o al servicio público, y no a fines privados (Bottaro y Sola Álvarez, 2018). 
Esta Ley dispuso la realización de un Inventario Nacional de Glaciares a cargo del Instituto Argentino de Nivología, Glaciología y Ciencias Ambientales (IANIGLA) 16; y prohibió todas aquellas actividades que podrían afectar a los glaciares y el ambiente periglacial, dentro de las cuales se incluyó la minería; asimismo, determinó que todas las actividades proyectadas en esas zonas, que no se encuentran prohibidas, estarán sujetas a un procedimiento de Evaluación de Impacto Ambiental y Evaluación Ambiental Estratégica, según corresponda; además, exigió que todas aquellas actividades prohibidas que se encontraran en ejecución debían someterse a una auditoría ambiental que identifique y cuantifique los impactos ambientales, y en caso de verificarse el impacto negativo sobre glaciares o ambiente periglacial, podría llegar a ordenarse el cese o traslado de las actividades.

Luego de su promulgación, la Ley de Glaciares continuó siendo resistida por la empresa Barrick Gold y algunos gobernadores de provincias mineras, quienes percibieron esa norma como un impedimento a la expansión de la minería en la zona andina. En particular, en noviembre de 2010, la trasnacional promovió una acción contra el estado argentino tendiente a que se declare la inconstitucionalidad de la Ley argumentando que infringía el Protocolo Adicional Específico para Pascua Lama en tanto violaba los derechos adquiridos de exploración y explotación en el marco de las Concesiones Mineras de ese emprendimiento. En la demanda afirmaba que esa norma le generaba un estado de incertidumbre acerca de las actividades que desarrollaba en las zonas en las que podrían existir glaciares o ambiente periglacial y que se verían afectados el patrimonio y sus derechos adquiridos (Isla Raffaele, 2015). Esta denuncia fue apoyada por el gobierno sanjuanino, quien adhirió a la demanda sosteniendo que la Ley excedía las competencias del Estado Nacional y que colisionaba con su ley de protección de glaciares ${ }^{17}$ y con la Constitución Provincial en relación con el manejo de los recursos naturales (Castro et al, en prensa).

Dos años después, en 2012, la Corte Suprema de Justicia de la Nación (CSJN) revocó las medidas cautelares que impedían la plena vigencia de la Ley de Glaciares. El Tribunal consideró que los fundamentos presentados eran contradictorios y que recién luego de que fuera presentado el Inventario de Glaciares y realizadas las

\footnotetext{
${ }^{16}$ El IANIGLA es una Unidad Ejecutora dependiente del CONICET, la Universidad Nacional de Cuyo y el Gobierno de la Provincia de Mendoza.

${ }^{17}$ Antes de que se sancionara la Ley Nacional de Glaciares, San Juan promulgó su propia ley de protección de glaciares con el fin de evitar la intervención nacional sobre los cuerpos de agua y delegar su evaluación y monitoreo a la autoridad local (Bottaro y Sola Álvarez 2018). Esta norma provincial reducía el objeto de preservación con respecto al proyecto de ley nacional, afirmaba que los glaciares eran patrimonio provincial, no prohibía explícitamente la minería y establecía la creación de un inventario provincial a cargo de una autoridad de aplicación local, el "Consejo Provincial de Coordinación para la Protección de Glaciares" (Isla Raffaele, 2015).
} 
auditorías ambientales, se podría conocer si la Ley afecta los derechos de la empresa minera $^{18}$ (Isla Raffaele, 2015). En respuesta a ello, el gobernador de San Juan dispuso la realización de la Auditoría Ambiental de Lama y Veladero en cumplimiento de lo establecido en la Ley nacional (Castro et al, en prensa). Esas auditorias fueron realizadas por instituciones provinciales y dieron como resultado que ninguno de los dos emprendimientos generaba daños sobre los glaciares y el ambiente periglacial (U.E.A.A., 2012), situación que le otorgó un marco legal a Barrick Gold para seguir operando a pesar de los eventos de contaminación generados en los años siguientes.

Entre 2015 y 2017 se hicieron públicos tres grandes derrames de solución cianurada originados en Veladero. Si bien fueron denunciados por la población local $^{19}$, la complicidad entre Barrick Gold y los poderes provinciales le ha permitido continuar explotando la mina sin mayores consecuencias; incluso se ha esquivado la clausura definitiva del emprendimiento, omitiendo lo dispuesto por el Código de Minería argentino en referencia a la cantidad de infracciones permitidas (Nazabal, 2019); asimismo, en 2017 la empresa firmó un acuerdo de cooperación con Shandong Gold (compañía estatal china especializada en minería subterránea) con el objetivo de potenciar nuevas inversiones en la región del Cinturón de Oro El Indio, donde se localizan, además de Veladero y Pascua Lama, otros proyectos binacionales como Del Carmen Alturas (Sí a la Minería, 2017; Lucero, 04/07/2017). En distintas oportunidades, el Gobierno sanjuanino ha demostrado su apoyo a la actividad y la empresa (Morales, 02/06/2018). Recientemente, luego de que se confirmara en Chile el cierre del Pascua Lama, funcionarios provinciales le solicitaron a Barrick Gold que evaluara la posibilidad de explotar el yacimiento del lado argentino (Leiva, 18/09/2020)

\section{Conclusiones}

El Tratado de Integración y Complementación Minera suscrito por Argentina y Chile, manifestó desde su origen, contradicciones con normas sensibles a la cuestión de soberanía nacional de ambos países, como el hecho de sobreponerse a la Ley de Defensa Nacional argentina que establece zonas de seguridad fronterizas y la Ley de Seguridad chilena; y con posterioridad, antagonizar con la Ley de Glaciales de

\footnotetext{
18 En junio de 2019, luego de concluido el primer Inventario Nacional de Glaciares, la CSJN confirmó la constitucionalidad de la Ley de Glaciares y dictaminó que la demanda presentada por Barrick Gold en 2010 resultaba inadmisible porque no había podido demostrar que la norma le causaba un agravio ni que lesionaba sus derechos adquiridos en el proyecto Pascua Lama (CSJN, 4/5/2019).

${ }^{19}$ Los pobladores de Jáchal (San Juan), organizados en la Asamblea Jáchal No Se Toca, ha realizado diversas acciones con el objetivo de que se cierre el emprendimiento Veladero. Dentro de ellas se destacan las demandas penales por violación a la Ley Nacional de Residuos Peligrosos - Ley 24.051- y a la Ley de Glaciares - Ley 26.639) (Isla Raffaele, 2019, Nazábal, 2019).
} 
Argentina, y con principios constitucionales invocados por diversos actores en contra de los efectos contaminantes que alteran las áreas andinas.

La Ley de Glaciares ha tensionado los objetivos del Tratado a partir de reconocer que no cualquier zona ni cualquier recurso puede ser circunscrito a la discrecionalidad de la Comisión Administradora ni de las empresas. Esta norma ambiental inhabilita la actividad minera en las zonas glaciares y periglaciales. Tal como evidenciaron los Estudios de Impacto Ambiental de Pascua Lama y Veladero, ambos propiedad de Barrick Gold, esos proyectos se encuentran asentados sobre esas geoformas; es decir, que deberían encontrarse alcanzados por la prohibición de las actividades extractivas de la Ley de Glaciares.

Por esa razón, la trasnacional desde un comienzo ha ejercido su influencia para obstaculizar la sanción e implementación de esa norma ambiental. En un principio presionó para vetar la Ley y luego, una vez aprobada, presentó una demanda argumentando su inconstitucionalidad amparándose en la existencia de la ley provincial y en la vigencia del Tratado, procurando imponer sus inversiones mineras por sobre la protección del ambiente. De este modo se reproduce un patrón ya presente en la sanción del Tratado de Integración y Complementación Minera, y es la influencia de Barrick Gold con su poder de lobby para generar primero las condiciones que habilitaron dicho Tratado con el fin de allanar la explotación minera transfronteriza y, posteriormente, presionar para impedir la plena aplicación de la Ley de Glaciares en Argentina.

Pese a la incompatibilidad con esta norma ambiental y a la contaminación generada por Barrick Gold en la mina Veladero, la empresa continúa operando bajo la complicidad de los poderes locales y provinciales. Ejemplo de ello, son la Ley Provincial de Protección de Glaciares de San Juan que no limitó ninguna actividad económica y las Auditorías Ambientales que afirmaron que las operaciones en Veladero y Pascua Lama no generan daño a los glaciares y ambientes periglaciales. Asimismo, las sentencias de los juzgados provinciales pretendieron no perjudicar a la multinacional, suspendiendo la vigencia de la Ley de Glaciares durante dos años y omitiendo el cese de la actividad, a pesar de superar la máxima cantidad de infracciones permitidas por el Código de Minería argentino. De esta forma, observamos cómo Barrick Gold ha implementado distintos mecanismos para sortear la normativa argentina y continuar con su actividad extractiva.

En la actualidad, el megaproyecto Pascua Lama, fuente de inspiración del Tratado binacional, se encuentra obstaculizado debido a que los estudios de impacto ambiental, favorables en su momento, vuelven a cuestionar, a la luz de los conflictos y contradicciones socioambientales; a pesar de que Chile no posee una norma específica de protección de glaciares, las comunidades diaguitas han logrado detener 
el proyecto con demandas judiciales a partir de las cuales la Superintendencia del Medio Ambiente clausuró definitivamente el emprendimiento debido los daños ambientales provocados durante su construcción. De esta forma, la paralización de Pascua Lama no se debió a las incompatibilidades con la Ley de Glaciares de Argentina, sino a la decisión del Tribunal de su país vecino.

En la línea de proyecciones sobre la riqueza mineral en la Cordillera de los Andes, cabe preguntarnos si el reciente acuerdo de cooperación estratégica entre Barrick Gold con Shandong Gold (especializada en minería subterránea) para operar en Veladero no es una estrategia para poder explotar el yacimiento Pascua Lama desde el lado argentino, teniendo en cuenta que el gobierno sanjuanino ha demostrado sus intenciones de continuar incentivando la actividad minera en la zona cordillerana.

Las tensiones en torno a esta actividad extractiva no sólo se evidencian en relación a algunas contradicciones con las legislaciones de cada país, con los intereses de corporaciones transnacionales, con la demanda de recursos a nivel nacional e internacional, con las comunidades y los diversos niveles de gobierno (nacional, provincial, local) sino que prevén otras si se problematiza desde los nuevos desafíos implicados en torno a la protección y sustentabilidad ambiental en la medida en que afectan fuertemente recursos no renovables. Cabe entonces preguntarnos, ¿Cuál es el presente y futuro de los emprendimientos mineros comprendidos en el Tratado Binacional si se encuentran sobre zonas glaciares y periglaciales, dentro del área de la Reserva de Biósfera San Guillermo y que afectan a comunidades de ambos lados de la Cordillera de los Andes?

\section{Referencias bibliográficas}

Acsebrud, E. (2012). Espacios particulares de acumulación en relación a la megaminería metalífera a cielo abierto. Revista Theomai, Número 25, Pp. 102-112.

Alcayaga, J. (2009). El país virtual: El lado oscuro del Tratado minero argentino-chileno. Editorial Tierra Mía. Santiago de Chile.

Aldunate Lizana, E. (2010). La posición de los Tratados Internacionales en el sistema de fuentes del ordenamiento jurídico chileno a la luz del derecho positivo. Revista Ius et Praxis, Año 6, Pp. 185-210.

Banco Mundial. (2013). Minería: resultados del sector. Recuperado de: http://www.bancomundial.org/es/results/2013/04/14/mining-resultsprofile

Bonasso, M. (2011). El Mal. Planeta. Buenos Aires, Argentina. 
Bottaro L. y Sola Álvarez M. (2018). Los vaivenes de la legislación protectora de glaciares en Argentina. Los conflictos por la megaminería más allá de la escala local. En Bottaro y Sola Álvarez (coord..), Agua y megaproyectos mineros en América Latina (Pp. 181-202). Ediciones UNGS, Universidad Nacional General Sarmiento. Buenos Aires, Argentina.

Brenning, A. y Azócar, GF. (2010). Minería y glaciares rocosos: impactos ambientales, antecedentes políticos y legales, y perspectivas futuras. Revista de Geografia Norte Grande, Vol. 47, pp. 143-158.

Bruculo, R. (2016). Integración trasandina: los Comités de Integración ATACALAR y Agua Negra en perspectiva comparada (1996-2012). Trayectorias e integración minera. Tesis doctoral. Universidad del Salvador. Argentina.

Castro, H; Isla Raffaele, ML; Nazábal, BG y Arqueros, MX. (En prensa). Políticas de escala en torno a normas ambientales. Reflexiones a partir de la implementación de la Ley de Glaciares en Argentina. En F. Martín y G. Merlinsky (comps), Conflictos y territorios hidrosociales en Argentina y América Latina. CLACSO. Buenos Aires, Argentina.

CEDHA. (2013). Los Glaciares de Barrick Gold: Informe Técnico sobre el Impacto de Barrick Gold en Glaciares en los Proyectos Mineros de Veladero y Pascua Lama, Por Daniel Taillant. Córdoba, Argentina.

CEPAL. (2002). Actualización de la compilación de leyes mineras de catorce países de América Latina y el Caribe. Eduardo Chaparro A. Compilador, Volumen I A., División de Recursos Naturales e Infraestructura, Santiago de Chile.

Corte Suprema de Justicia (CSJN). (24/04/2012). «Vargas, Ricardo Marcelo contra San Juan Provincia de y otros sobre Daño Ambiental». CSJ 175/2007 (43V)/CSI.ORI

Corte Suprema de Justicia (CSJN). 4/5/2019. «Barrick Exploraciones Argentinas S.A. y otro c/ Estado Nacional s/ acción declarativa de inconstitucionalidad». CSJ 140/2011 (47-B)/CS1 ORI.

Decreto Ley N¹5.385/1944. Creación de Zonas de Seguridad, República Argentina. Decreto Ley $\mathrm{N}^{\circ} 1.939 / 1977$. Normas sobre Adquisición, Administración y Disposición de Bienes del Estado, República de Chile.

Diario de Cuyo. (21/06/2017). Doce claves para entender el Acuerdo Federal Minero. Recuperado de https://www.diariodecuyo.com.ar/suplementos/Doceclaves-para-entenderel-Acuerdo-Federal-Minero-20170620-0088.html

Díaz Gavier, M. (2012). Politica exterior minera argentina en el proyecto Pascua Lama: de Menem a Cristina Fernández de Kirchner (1991-2012). Trabajo Final para la Maestría en Relaciones y Negociaciones Internacionales. FLACSO Universidad de San Andrés en cooperación con la Universidad de Barcelona 
Drnas de Clément, Z. (s/f). Constitución Nacional y jerarquía de los Tratados Internacionales. Academia Nacional de Derecho y Ciencias Sociales de Córdoba (Argentina). Recuperado de http://www.acaderc.org.ar/doctrina/articulos/artconstitucionnacional

Espizúa, L; Ferri Hidalgo, L; Gargantini, H; Pitte, P. e Irusta, O. (2006). Ambiente y procesos glaciales y periglaciales en Lama-Veladero, San Juan, Argentina. 62 páginas, 13 mapas. Encargado por: Subsecretaría de Minería, Gobierno de la Provincia de San Juan.

Giarracca, N. y Teubal, M. (2010). Disputas por los territorios y recursos naturales: el modelo extractivo. Revista ALASRU Nueva Época No 5, Pp. 113-133.

Gudynas, E. (2009). Diez tesis urgentes sobre el nuevo extractivismo. Contextos y demandas bajo el progresismo sudamericano actual. En Centro Andino de Acción Popular (CAAP) y Centro Latino Americano de Ecología Social (CLAES), Extractivismo, politica y sociedad. Ecuador. Pp.187-225.

Gudynas, E. (2012). Estado compensador y nuevos extractivismos. Las ambivalencias del progresismo sudamericano. Nueva Sociedad, Núm. 237, Pp.128-146.

Harvey, D. (2007). Cap. VI: El neoliberalismo a juicio. En Harvey, Breve historia del neoliberalismo. Madrid: Akal, Pp. 159-187

Isla Raffaele, ML. (2015). El papel de la Ley de Glaciares en las disputas por la Megaminería en Argentina. Tesis de grado. Facultad de Agronomía, Universidad de Buenos Aires. Argentina.

Isla Raffaele, ML. (2019). Procesos de [des/re]territorialización en Iglesia y Jáchal a partir de la instalación del emprendimiento Veladero (San Juan, Argentina, 2004-2019). Revista del CESLA, International Latin American Studies Review, Núm. 23, Pp. 89-110.

Keohane y Nye. (1988). Poder e interdependencia. Grupo Editor Latinoamericano. Buenos Aires, Argentina.

Knight Piésold. (2002). Informe de Impacto Ambiental del emprendimiento minero Veladero - Etapa de explotación.

Knight Piésold. (2006). Informe de Impacto Ambiental del emprendimiento minero Pascua Lama - Etapa de explotación.

Leiva, C. (18/09/2020). El Gobierno pide que se explote el lado argentino por la caída de Pascua-Lama. Diario de Cuyo. Recuperado de https://www.diariodecuyo.com.ar/economia/El-Gobierno-pide-que-seexplote-el-lado-argentino-por-la-caida-de-Pascua-Lama--202009170115.html

Ley N²6.418/2010. Régimen de Presupuestos Mínimos para la Protección de los Glaciares y del Ambiente Periglacial. República Argentina. 
Ley N²6.639/2010. Régimen de Presupuestos Mínimos para la Preservación de los Glaciares y del Ambiente Periglacial. República Argentina.

Lucero, J. (04/07/2017). Shandong Gold desembarcó en Veladero y se hizo cargo de la mina de oro. Agencia de noticias Telam. Recuperado de https://www.telam.com.ar/notas/201707/194362-san-juan-shandonggold-veladero.html

Machado Aráoz, H. (2010). "El agua vale más que el oro”: Grito de resistencia decolonial contra los nuevos dispositivos expropiatorios. En Delgado, GC (Comp.), Ecología Política de la Minería en América Latina. Centro de Investigaciones Interdisciplinarias en Ciencias y Humanidades, Universidad Nacional Autónoma de México. México. Pp. 59-96.

Martin, F. y Healey, M. (2020). La Ley de Glaciares en la encrucijada. Cuestión minera y juridificación del conflicto ambiental en Argentina. En Merlinsky, G (Comp.), Cartografias del conflicto ambiental en Argentina III. Ediciones Ciccus. CLACSO. Pp. 157-186

Minería en números. (2012). Secretaría de Minería. Ministerio de Planificación Federal, Inversión Pública y Servicios. Argentina.

Ministerio de Hacienda y Finanzas Públicas (2016). Informes de cadenas de valor (Año 1, №2), Minería Metalífera y Rocas de Aplicación. Argentina.

Morales, A. (02/06/2018). Uñac recibió al presidente de Shandong Gold. Servicio

Informativo Gobierno de San Juan. Recuperado de https://sisanjuan.gob.ar/prensa/2018-06-02/8236-unac-recibio-alpresidente-de-shandong-gold

Nazabal, BG. (2019). El agua vale más que el oro. Estrategias de resistencia de la Asamblea Jáchal No Se Toca (2015-2018). Tesis de grado. Facultad de Agronomía, Universidad de Buenos Aires. Argentina.

Prado, O. (2005). Situación y perspectivas de la Minería en Argentina. Serie Recursos Naturales e Infraestructura. CEPAL. Santiago de Chile.

Rodríguez Pardo, J. (2011). Vienen por el oro, vienen por todo: Las invasiones mineras 500 años después. Ediciones CICCUS, 2da edición, Buenos Aires, Argentina.

Rojas, F y Wagner, L. (En prensa). Inventario de glaciares en Argentina: polémicas públicas y disputas de sentido. En Marina Miraglia y Ana Marcela Franca (comp), Paisaje y patrimonio: impresiones de la historia en el ambiente natural. Universidad Nacional de Quilmes, TESEO, Buenos Aires., Argentina.

Seguí, D. (2016). Derrame de cianuro en Veladero. En FARN, Informe Ambiental Anual 2016. Pp. 202-214 
Seoane, J. (2012). Neoliberalismo y ofensiva extractivista: Actualidad de la acumulación por despojo, desafíos de Nuestra América. Revista Theomai, Número 26.

Sí a la Minería. (2017). La empresa china Shandong Gold compró el 50 por ciento de Veladero. Sí a la Minería. Recuperado de https://sialamineria.com/contenido/129/la-empresa-china-shandonggold-compro-el-50-por-ciento-de-veladero

Svampa, M. (2008). Movimientos Sociales, matrices socio-políticas y nuevos escenarios en América Latina. I Jornadas de Análisis Crítico, Universidad del País Vasco.

Svampa, M y Álvarez, S. (2010). Modelo minero, resistencias sociales y estilos de desarrollo: los marcos de la discusión en la Argentina. Ecuador Debate, 79. Abril 2010.

Svampa, M. y Antonelli, M. (2009). Introducción: Hacia una discusión sobre la megaminería a cielo abierto. En Svampa y Antonelli (Comp.), Minería transnacional, narrativas del desarrollo, resistencias sociales. Editorial Biblos. Buenos Aires, Argentina. Pp15-27.

Svampa, M; Bottaro, L., Sola Álvarez, M. (2009). La problemática de la minería a cielo abierto: modo de desarrollo, territorio y discurso dominantes. En Svampa y Antonelli (Comp.), Minería transnacional, narrativas del desarrollo y resistencias sociales. Editorial Biblos. Argentina. Pp. 29-50.

Svampa, M. y Viale, E. (2014). El modelo minero como figura extrema del extractivismo. En Svampa y Viale, Maldesarrollo. Katz Editores. Argentina. Pp 171-245.

U.E.A.A - Unidad Especial de Auditoría Ambiental (2012). Informe de Auditoria Conjunta de los Proyectos Veladero y Pascua-Lama (Sector Lama). Provincia de San Juan.

Villamil Velázquez, JF. (2012). Consolidación de la gran minería trasnacional en Latinoamérica. Revista Theomai, Núm. 25, Pp. 46-57.

Wagner, L. 2010. Problemas Ambientales y Conflicto Social en Argentina. Movimientos Socioambientales en Mendoza. La defensa del agua y el rechazo a la megaminería en los inicios del siglo XXI. Tesis doctoral. Universidad Nacional de Quilmes.

Yornet, Y. (2016). Desafíos de la responsabilidad ambiental. Caso Vargas Ricardo Marcelo contra San Juan Provincia y otros sobre daño ambiental. Cuaderno De Derecho Ambiental, Núm. VII (2015), Pp. 179-206. 